\title{
Contribuições de Viktor Emil Frankl ao conceito de resiliência'
}

\author{
Viktor Emil Frankl's contribution to \\ the concept of resilience
}

\author{
Daniel Rocha SILVEIRA ${ }^{2}$ \\ Miguel MAHFOUD²
}

\begin{abstract}
Resumo
Trata-se de um estudo sobre resiliência-capacidade do ser humano de enfrentar, sobrepor-se e ser fortalecido por experiências de adversidade que tem por objetivo discuti-la de acordo com a visão de Viktor Emil Frankl: a logoteoria. Descrevem-se vários conceitos de resiliência e a questão dos fatores de risco e fatores protetores. Em seguida, faz-se um estudo da logoteoria destacando os conceitos que tornam possível a resiliência: a dimensão noética do homem, visto como unidade múltipla, do que decorre a força de resistência do espírito e a responsabilidade; a busca de sentido como motivação primária; a autotranscendência e o autodistanciamento propiciado pelo humor e pela autocompreensão. Conclui-se que a resiliência torna-se uma das conseqüências de se encontrar o sentido da vida e movimentar-se para realizá-lo, permitindo dizer um "sim" à vida apesar de tudo.
\end{abstract}

Uniterms: Auto-distanciamento. Auto-transcendência. Motivação. Psicologia. Resiliência. Resistência.

\begin{abstract}
This is a study about resilience- the human capacity to face, to overcome and to gain strength through experiences of adversity-which aims to discuss the issue according to the views of Viktor Emil Frankl: (logotheory). Various concepts of resilience are described, as is the issue of risk factors and protective factors. There then follows a study on logotheory, highlighting the concepts which make resilience possible: the human being's noetic dimension, man seen as a multiple unit, from which comestrength of spirit and responsibility; the search for meaning as the primary motivation; self-transcendence; self-distancing-provided by humor and self-comprehension. In conclusion, resilience becomes one of the consequences of finding a meaning for life and moving towards its fulfillment, which makes it possible to say "yes" to life, despite everything.
\end{abstract}

Uniterms: Self-distancing. Self-transcendence. Motivation. Psychological. Resilience. Resistence.

O mundo da alta modernidade "está repleto de riscos e perigos, para os quais o termo 'crise' - não como mera interrupção, mas como um estado de coisas mais ou menos permanente - é particularmente adequado" (Giddens, 2002, p.19).
A crise e a dor, que perpassam a subjetividade, tornam-se foco de interesse das ciências, em especial a psicologia, que busca, por meio de estudos e pesquisas, compreender e dar respostas ao ser humano. Este reflete e se pergunta: por que existe a dor? Ela é meramente

\section{UVR}

1 Artigo elaborado a partir da dissertação de D.R. SILVEIRA, intitulada "O sentido da resiliência: a contribuição de Viktor E. Frankl". Universidade Federal de Minas Gerais, 2006.

2 Universidade Federal de Minas Gerais, Faculdade de Filosofia e Ciências Humanas, Curso Psicologia Social. Av. Antônio Carlos, 6627, 31270-901, Belo Horizonte, MG, Brasil. Correspondência para/Correspondence to: D.R. SILVEIRA. E-mail: <danielrosilveira@globo.com>. 
destrutiva, ou é possível transformá-la em oportunidade de crescimento?

Olhando cuidadosamente ao redor, podem-se identificar pessoas e sociedades que superaram e superam seus sofrimentos. Existem testemunhos que o atestam: comunidades e indivíduos que cresceram com experiências difíceis e superaram os obstáculos, alcançando realização com criatividade e esperança.

Uma população altamente vulnerável em situação de violência e pobreza foi acompanhada durante mais de trinta anos por pesquisadores, na ilha de Kauai, Hawai. Surpreendentemente, um terço destas pessoas não sofreu danos psíquicos. Esses pesquisadores (Infante, 2002)(3) imediatamente qualificaram-nas como "crianças invulneráveis" e buscaram um nome que melhor adjetivasse esta invulnerabilidade. Encontraram na física a palavra resiliência, que significa "propriedade que alguns corpos apresentam de retornar à forma original após serem submetidos a uma deformação elástica" (Houaiss \& Villar, 2001, p.2437). Aquelas crianças teriam voltado à forma original após serem submetidas à força das adversidades (Infante, 2002).

Logo a expressão "crianças invulneráveis" mostrou-se inadequada, já que havia vulnerabilidades. Os achados científicos mostraram que a resiliência não é um atributo fixo ou um traço de personalidade, mas sim algo que se constrói como um tecido no espaço entre o indivíduo e a sociedade. Não é somente individual, nem somente social. Envolve outras pessoas, é dinâmica e forma-se sempre com a presença de um outro humano que dê suporte à pessoa que sofre, oferecendo uma escuta compreensiva, uma presença motivadora (Canelas, 2004; Cyrulnik, 2001; Infante, 2002).

Surgiu na psicologia um novo campo de investigação, que voltou o olhar para as pessoas em adversidades, atentando para os recursos, as fontes de saúde e os processos motivadores de adaptação positiva, entendendo a adaptação não como conformidade social, mas como a transformação ativa da sociedade, de forma construtiva (Melillo, 2004b).

Na história da humanidade, os grandes resilientes foram justamente aqueles homens e mulheres que se propuseram mudar a sociedade e a cultura em que viviam, assumindo em si mesmos a tarefa de plasmar na sociedade seus próprios valores e ambições de transformação. ... O sujeito resiliente é um sujeito crítico de sua situação existencial (Galende, 2004, p.60).

A resiliência passou a ser então uma nova lente, uma nova chave de compreensão da experiência humana que, intrinsecamente, vem marcada pelo sofrimento.

Uma metáfora que ilustra esta trajetória é o livro de Jó, da Bíblia, no qual um ser humano é provado até as últimas conseqüências, como ferro em brasa sofrendo as vigorosas marteladas do ferreiro para que daí surja uma ferramenta refinada, ou como o mármore que recebe os duros golpes de cinzel e martelo do escultor para ser transformado em uma bela escultura.

Este artigo tem como objetivo discorrer sobre o homem naquilo que tem de mais específico e que torna possível a resiliência. E, para isto, alude à visão teórica do psiquiatra Viktor Emil Frankl, sobrevivente de quatro campos de concentração, pessoa altamente resiliente, que traz uma contribuição relevante na compreensão do ser humano, cuja especificidade permite que surja a resiliência (Frankl, 1946/1989a, 1989b, 1990, 1991a, 1991b, 1948/1993, 1969/1998, 2006).

Quais são as características especificamente humanas que tornam possível a superação das adversidades?

\section{A resiliência}

As pesquisas sobre resiliência tiveram início no hemisfério norte, assumindo nos Estados Unidos e Inglaterra uma perspectiva comportamentalista, pragmática, centrada no indivíduo. Estendendo-se por toda a Europa, receberam enfoques psicanalíticos. E, chegando à América Latina, tornaram-se enfocadas na comunidade, como uma forma de reação aos problemas sociais. No início das pesquisas, em geral, havia uma ênfase na infância; depois se abrangeram outras etapas da vida, bem como problemas mais específicos, por exemplo, violência e incapacidade (Melillo, Ojeda \& Rodríguez, 2004).

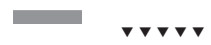

3 Citação de Infante (2002) do seguinte original: Werner, E. \& Smith, R. (1982). Vulnerable but invincible: a longitudinal study of resilient children and youth. 568 New York: McGraw-Hill Book. 
Mas, o que é resiliência? Qual é precisamente a sua definição?

\section{Conceito}

No âmbito das Ciências Sociais, existem várias definições de resiliência. Seguem algumas delas:

A resiliência é uma habilidade para ressurgir diante das adversidades, adaptar-se, recuperar-se e aceder a uma vida significativa e produtiva (Kotliarenko, Fontecilla \& Cáceres, 1997, p.5).

Resiliência é o enfrentamento efetivo de circunstâncias e eventos de vida severamente estressantes e acumulativos (Kotliarenko et al., 1997, p.5).

Boris Cyrulnik, psicanalista francês, visualiza a resiliência como um oxímoron, em que o sujeito é cindido por um trauma, mas se reconstrói e resiste; sofre, mas tem esperança apesar de tudo. Explica que oxímoron é uma figura de linguagem que "consiste em reunir dois termos antinômicos" (p.21). Por exemplo, a expressão:"a obscura claridade"(Cyrulnik, 2001, p.21).

Para Cyrulnik (2001), a resiliência é um processo íntimo que se integra a um processo social. É um tecido e pertence à família dos mecanismos de defesa; é controlável e traz esperança. O conceito de resiliência poderia ser resumido em "mola" e "tecido". "Mola" porque, ao receber o impacto da adversidade, a pessoa sofre (de certa maneira "deforma-se", como a mola ao receber uma força: quando a mola é presa a um peso, por exemplo, estica, mas depois volta) e depois supera o sofrimento, salta superando o fator que ameaça a pessoa. "Tecido" porque se configura no espaço entre a pessoa e seu entorno social (especialmente as pessoas significativas com quem é possível estabelecer uma relação de apego seguro), como um mosaico de pano que vai sendo tecido. Como mola e tecido, a cada impacto, é possível buscar a superação, ou seja, "apesar do sofrimento, buscamos a maravilha" (p.194).

Sintetizando, define-se aqui a resiliência como a capacidade de transformar uma situação de dor em possibilidade de crescimento, ou "capacidade humana para enfrentar, sobrepor-se e ser fortalecido ou transformado por experiências de adversidade" (Grotberg, 2002, p.20). Para Melillo (2004b), é a "capacidade de enfrentar a adversidade e sair fortalecidos desta prova" (p.77).

\section{Os fatores protetores}

Desde a primeira geração de pesquisadores da resiliência, procura-se identificar os fatores de risco e os de proteção (Infante, 2002).

Fatores de risco são:

influências que ocorrem em qualquer nível sistêmico (família, indivíduo, comunidade, sociedade) que ameaçam os resultados de adaptação positivos. Os fatores de risco estão relacionados com toda sorte de eventos negativos de vida e operam de maneiras diferentes em diferentes períodos de desenvolvimento do indivíduo. ... Não constituem uma variável por si só, devendo ser pensados sempre como um processo (Canelas, 2004, p.49).

Por outro lado,"fatores ou mecanismos de proteção são condições do ambiente capazes de favorecer o indivíduo ou um grupo e de reduzir efeitos ou circunstâncias desfavoráveis" (Canelas, 2004, p.57).

Rutter considera "os mecanismos de proteção, entendendo por eles não a valência contrária aos fatores de risco, mas aquela dinâmica que permite ao indivíduo sair fortalecido da adversidade, em cada situação específica e respeitando as características pessoais" (Infante, 2002, p.34).

Canelas (2004) afirma que "uma perspectiva ecossistêmica sugere que influências protetivas podem ser introduzidas na vida de um indivíduo através de qualquer relação em qualquer parte do ecossistema" (p. 109). Vale ressaltar que se entende por ecossistema humano o sistema social em que está inserido o homem - incluindo família, indivíduo, comunidade e sociedade. Canelas (2004) acrescenta que a resiliência pode ser aprendida e desenvolvida por qualquer pessoa.

Cuestas, Estamatti e Melillo (2002) afirmam que as definições de resiliência enfatizam os seguintes fatores protetores do resiliente: "adaptabilidade, baixa suscetibilidade, enfrentamento efetivo, capacidade, resistência à destruição, condutas vitais positivas, temperamento especial e habilidades cognitivas" (p.86).

Sem dúvida, todas as pesquisas apontam que, entre os fatores protetores, o mais importante está em um relacionamento de apego seguro entre o sujeito resiliente e uma pessoa significativa (Canelas, 2004; Galende, 2004; Kotliarenco \& Lecannelier, 2004; Melillo, 2004a). 
Rodríguez (2002) afirma que para se compreender o resultado resiliente podem-se isolar fatores protetores que, interagindo, produzem a resiliência. Porém, esta interação em si não é suficiente para deslanchar o processo de resiliência. Segundo ele, a resiliência, "como resultado tanto individual quanto grupal, como resposta criativa de superação de situações adversas, é algo mais que a soma dos fatores de resiliência que a promovem, e ... supõe a existência de um imponderável ..., que determinará o resultado final" (Imponderável, aqui, refere-se a um fator que não pode ser previsto) (Rodríguez, 2002, p.189).

\section{Quem é o homem na visão de Viktor Frankl?}

Para responder a esta questão, parte-se do referencial de Viktor Frankl, que criou a chamada análise existencial (Existenzanalyse), que tem como objetivo o esclarecimento da existência, enfatizando possibilidades de se realizar o sentido da vida. Essa análise difere da análise da existência (Daseinanalyse), que não enfoca especificamente o sentido da vida, e sim um "esclarecimento do ser" (Frankl, 1991a, p.61).

A obra de Viktor Frankl, fundador da terceira Escola Vienense de Psicoterapia (depois das de Freud e Adler), pode ser chamada também de Logoterapia (Logo: sentido/Terapia: cura) e baseia-se no conceito de que a vida tem sentido (Frankl, 1946/1989a; Xausa, 1988). A teoria formulada nesta obra é chamada de logoteoria.

Enquanto a psicanálise menciona a adaptação do homem-pulsional à realidade e a psicologia individual alude ao homem que se configura responsável e corajoso frente ao mundo, a logoteoria enfoca o noético (palavra que vem do grego "noos" que significa "mente", e aqui é usada como "espiritual": a dimensão dos fenômenos especificamente humanos, como a liberdade para descobrir o sentido da própria vida, a autotranscendência, o autodistanciamento, a decisão, a capacidade de amar etc.) (Frankl, 1946/1989a).

A logoteoria afirma a "autonomia da existência espiritual" e disso decorre o "senso de responsabilidade". O ser humano é, em essência, ser-responsável (Frankl, 1948/1993, p.15), e a responsabilidade está na ação no momento presente ("aqui e agora"), na "concretude de determinada pessoa numa determinada situação" (p.16).
Humano é, também, o "ser que decide" (Frankl, 1948/1993, p.26). Somente diante daquilo que é decisão sua a pessoa é responsável, e somente quando ela é responsável, pode-se dizer que está sendo "ela mesma". "O ser humano propriamente dito começa onde deixa de ser impelido, e cessa quando deixa de ser responsável" (p.19).

A existência humana direciona-se sempre para "além de si mesma, indicando um sentido". Então, o importante é primeiramente realizar um sentido, ou seja, é importante que a pessoa assuma atitudes que a aproximem da realização daquilo que tem sentido (Frankl, 1948/1993, p.61).

A existência em si é espiritual, enquanto a"facticidade" é formada "tanto de elementos psicológicos quanto fisiológicos; contém 'fatos'tanto psíquicos como corporais" (Frankl, 1948/1993, p.20). Há possibilidade de todo ser humano assumir uma atitude diante dos condicionamentos, diante da "facticidade", atitude esta que pode configurar a chamada força de resistência do espírito (Frankl, 1946/1989a). Esta atitude decorre de a pessoa ter sua existência espiritual mobilizada no sentido de uma"responsabilidade livre, contrapondo-a aos condicionamentos da facticidade psicofísica, que o paciente tende a aceitar como seu destino" (Frankl, 1948/1993, p.20).

Em relação aos condicionamentos físicos, psicológicos e sociológicos, o homem pode sempre se posicionar. Sendo um ser histórico, ou seja, determinado por condições sociológicas e também por condições biológicas e psicológicas, o homem ainda assim é livre para buscar o sentido de sua vida (Frankl 1946/1989a).

Frankl descreve o ser humano como uma unidade múltipla. A pessoa é um ser "único e total" (Xausa, 1988, p.116) e nela estão integradas as dimensões psíquica (anímica), corporal (biológica) e noética (Frankl, 1991a; Peter, 1999).

\section{O homem e sua motivação primária: a busca de sentido}

Todo ser humano tem a vontade de buscar um sentido para a vida, e esta vontade é precisamente a principal força motivadora da pessoa. No momento em que a pessoa se pergunta sobre o sentido da vida, expressa o que há de mais humano em si (Frankl, 1946/1989a). 
O sentido diz respeito à totalidade da vida de uma pessoa e também ao momento presente. Existe também um sentido último, mais amplo - o sentido da totalidade da vida de todos. Pode-se utilizar a seguinte metáfora: um filme é feito com milhares de fotos. Cada uma tem um sentido, mas o sentido do filme todo só será compreensível ao final da exibição. Então, só é possível compreender o sentido da vida de uma pessoa como um todo no encerramento desta vida, ou após o encerramento (Frankl, 1948/1993).

Cada pessoa é única e insubstituível, então, o sentido é exclusivo e específico de cada um. Frankl (1946/1989a) explicita o fato de que o sentido diz respeito àquilo que a pessoa é chamada a realizar em um determinado momento. O sentido a ser realizado no momento é transitório, ou seja, precisa ser cumprido naquele instante. Ademais, existe o caráter de autotranscendência do sentido, ou seja, diz respeito a algo ou a alguém que está fora da pessoa.

Quando a pessoa encontra o sentido de sua vida, encontra aquilo que pode fazer e que exprime sua unicidade, a sua missão diante da vida. E, ao desempenhar no cotidiano aquilo que é seu sentido, realiza-se plenamente como ser humano, atuando com suas possibilidades mais peculiares. A realização pessoal vem como conseqüência de se atingir o sentido (Frankl, 1946/1989a).

A pergunta sobre o sentido da vida deve ser feita de forma concreta, contextualizada, de acordo com a situação da pessoa, onde ela está e no momento em que ela está (Frankl, 1946/1989a). É a vida que interroga ao ser humano sobre o sentido de sua vida, e não o contrário (Frankl, 1948/1993).

Para Frankl (1946/1989a), a pessoa conhece a si mesma na medida em que vai cumprindo suas tarefas cotidianas e que vive o que tem sentido em cada situação. Em muitos casos, "a vida ter sentido" significa "na vida ter tarefas a cumprir" (Frankl, 1948/1993, p.70).

O sentido precisa ser encontrado, descoberto, e não criado (Frankl, 1946/1989a).

A percepção do sentido em um determinado momento assemelha-se à concepção de figura e fundo na psicologia da Gestalt e à experiência do "insight" (Frankl, 1993). O sentido é uma possibilidade que se destaca do pano de fundo da realidade. Em cada situação há um "caráter de exigência" imanente para se descobrir o sentido (Frankl 1989, 1948/1993).

Além do sentido de situações únicas, existem os "universais de sentido", os valores (Frankl, 1946/1989a, p.79). Frankl classifica-os em três categorias: os valores criativos (pelos quais o homem dá algo ao mundo, por meio da ação concreta, da realização de algo - por exemplo, no trabalho); os valores vivenciais (pelos quais o homem recebe algo do mundo, frui do que há de belo, como uma paisagem natural, um pôr-do-sol, um filme, ou quando o sujeito se entrega à pessoa amada); e os valores de atitude (a pessoa pode se posicionar de forma digna frente ao sofrimento inevitável) (Frankl, 1946/1989a).

Ao olhar para o passado, a pessoa pode encontrar o sentido e a realização naqueles momentos que foram bem vividos (nos quais se realizou o sentido). O passado torna-se, então, um "celeiro" onde se armazenam momentos cheios de sentido e que não podem ser retirados da pessoa, pois já são realidade consumada (Frankl, 1948/1993).

A vida tem sentido como um todo, então o sofrimento inevitável tem também seu sentido. O sofrimento faz parte da vida. Deve-se ressaltar aqui que a dor que pode ser evitada deve ser evitada, do contrário seria masoquismo (Frankl, 1948/1993). O sentido é possível mesmo se há sofrimento. E, de fato, há situações - por exemplo, em estados de doença terminal - nas quais a única possibilidade que resta ao ser humano é a de se posicionar com dignidade (Frankl, 1946/1989a, 2006).

Em momentos de sofrimento inevitável extremo, o que se requer da pessoa é que suporte a incapacidade de compreender racionalmente que a vida tem um sentido incondicional, não obstante as circunstâncias. Este sentido incondicional é chamado de supra-sentido. Só é apreendido pela fé, pela confiança, pelo amor (Frankl, 1989a). Ou seja, o supra-sentido não pode ser compreendido pelo raciocínio que responde à pergunta do "por quê?" (por que aconteceu a doença terminal, a catástrofe natural, a situação inesperada?) (Frankl, 1948/1993).

Referente à dimensão do supra-sentido, a religião autêntica torna-se uma grande força de segurança para o homem: "a segurança e a ancoragem na transcendência, no Absoluto" (Frankl, 1946/1989a, p.297). 
Para Viktor Frankl, o homem religioso é aquele que foi capaz de completar a sua dinâmica ontológica. É responsável e consciente, vive sua vida como uma missão a ser cumprida. Então, na busca de sentido, coloca-se a experiência religiosa (Coelho Junior \& Mahfoud, 2001). A pessoa que busca uma religiosidade sadia encontra tradições e valores que a direcionam a um relacionamento com o que ela considera ser "o criador", e isto, portanto, torna-a aberta ao outro e à transcendência. Com isto, realiza-se melhor o sentido de sua vida que, segundo esta concepção, apresenta uma missão para casa pessoa, que inclui esta abertura supracitada. Por isso, diz-se que o homem religioso foi capaz de completar a sua dinâmica ontológica.

\section{O autodistanciamento e a autotranscendência}

O autodistanciamento é uma característica especificamente humana. Diz respeito à "capacidade do homem de distanciar-se de si próprio" (Frankl, 1989b, p.43).

É possível ao ser humano distanciar-se de si, por exemplo, por meio do humor - a capacidade de rir ou sorrir apesar da tragédia. Quando o sujeito ri de seus problemas provoca uma distância entre o núcleo do seu "eu" e a situação problemática. O humor possibilita ao homem tornar-se "senhor de si" (Frankl, 1946/1989a, p.327). O homem coloca-se "acima de uma situação" para dominá-la (p.225).

O autodistanciamento ocorre também pela autocompreensão. À medida que a pessoa se compreende, torna-se capaz de distanciar-se de si mesma. Por exemplo, diante de impulsos agressivos, a pessoa pode se posicionar e escolher o que fazer, para depois agir (Frankl, 1989b).

A autotranscendência também faz parte da essência do ser humano - a pessoa é aberta ao mundo, coloca-se em relação, volta-se para algo ou alguém diferente de si. "Ser homem significa ... ser para além de si mesmo.... Ser humano significa ordenar-se em direção a algo ou a alguém: entregar-se ... a uma obra a que se dedica, a uma pessoa que ama, ou a Deus, a quem serve" (Frankl, 1946/1989a, p.45).

Então, a autotranscendência mostra que o ser humano não se fecha em condicionamentos, mas trans-

572 cende os condicionamentos psicofísicos.
"A existência vacila ou desmorona se não for vivida esta qualidade da auto-transcendência" (Frankl, 1989b, p.41). A experiência de Viktor Frankl como prisioneiro de campos de concentração atesta esta realidade (Frankl, 2006).

Experiências vividas em outros campos de prisioneiros, como os norte-vietnamitas, confirmam que a sobrevivência dependia da "capacidade de orientar a própria vida em direção a um 'para que coisa' ou um 'para quem'"'(Frankl, 1989b, p. 29).

O interesse mais profundo do ser humano não é olhar para si mesmo, mas volver o olhar para o mundo exterior, em busca de um sentido. A pessoa se auto-realiza justamente na proporção em que "esquece de si mesmo" enquanto se dedica a um trabalho ou a uma pessoa (Frankl, 1948/1993, p.78). Por exemplo, no encontro amoroso entre duas pessoas, o sujeito pode intuir a unicidade do outro (Frankl, 1989b).

\section{A força desafiadora do espírito: o homem resiliente}

Na explicação de Cyrulnik (2001) sobre a resiliência como oxímoron, uma parte da pessoa, sofrendo um revés, produz necrose (degenera), enquanto outra parte"reúne, com a energia do desespero, tudo o que pode continuar dando um pouco de felicidade e de sentido à vida" (Cyrulnik, 2001, p.21).

Para Viktor Frankl, conforme já explicado, a principal força motivadora do ser humano é a busca por um sentido para a vida (Frankl, 1948/1993). Toda a dinâmica da vida de uma pessoa parte primordialmente da vontade de descobrir um sentido para a sua existência (Frankl, 1946/1989a, 1990).

Walsh (2004) afirma que o corpo e a alma da resiliência encontram-se no sistema de crenças pessoal e familiar, e deste sistema faz parte a atitude de dar sentido à adversidade - considerar a crise um desafio significativo, compreensivo e manejável. Desta forma, é preciso ter a percepção de que o sofrimento tem seu sentido. No caso de poder ser evitado, deve sê-lo. E quando é inevitável, deve-se aceitá-lo. Walsh (2004) escreve: "dominar o possível, aceitar o que não se pode mudar" (p.88). E tudo isto deve ocorrer mantendo-se o otimismo diante das dificuldades - o que está de acordo 
com a visão de Frankl, pois o pressuposto da vida de uma pessoa é a questão do sentido (Frankl, 1948/1993).

Se a principal força motivadora do ser humano é a busca do sentido da vida (Frankl, 1948/1993), é a busca deste sentido a raiz da motivação para a pessoa construir resiliência. "Não se pode conceber algo que condicione o ser humano a ponto de deixá-lo sem a menor liberdade.... O ser humano, em última análise, se determina a si mesmo. Aquilo que ele se torna - dentro dos limites dos seus dons e do meio ambiente - é ele que faz de si mesmo" (Frankl, 2006, pp.113).

Apesar dos condicionamentos, a pessoa sempre mantém a liberdade de se posicionar, a liberdade de escolher o que quer ser dentro das fronteiras que a vida impõe.

Na verdade, como escreve Rodríguez (2002), na medida em que os pesquisadores foram isolando os fatores promotores de resiliência encontraram fatores em si mesmos óbvios, quase de senso comum. Então, restou a pergunta: o que determina o resultado final da resiliência?

Na fórmula da resiliência proposta por este autor existe um fator que não pode ser definido: o imponderável. Este imponderável está exatamente na liberdade do ser humano para escolher encontrar ou não um sentido para a vida (Frankl, 1946/1989a, 1948/1993, 2006). O encontro deste sentido pode ser percebido fenomenologicamente (Frankl, 1998), ou alguns de seus atributos podem ser quantificados por meio de um teste desenvolvido para este propósito - o Logotest (Lukas, 1996).

Este sentido pode ser encontrado em três caminhos, como citado anteriormente: nos valores criativos, vivenciais e de atitude, que são realizados a cada momento presente, respondendo às situações que a vida apresenta (Frankl, 1946/1989a, 1948/1993).

A partir do imponderável (Rodríquez, 2002), que compreende a liberdade humana, a busca de sentido, a força de resistência do espírito (Frankl, 1946/1989a, 1990, 2006) encontra-se um sentido e, após isto, buscam-se os chamados pilares da resiliência - "atitudes que facilitam a resiliência" (Vanistendael \& Lecomte, 2004, p.91).

A resiliência significa: "Comprometer-se em uma nova dinâmica de vida. ... Por isto, a noção de sentido tem tanta importância, até o ponto de constituir, para muitos, uma necessidade quase vital. O vínculo e o sentido são os dois fundamentos básicos da resiliência" (Vanistendael \& Lecomte, 2004, p.91).

Por outro lado, em todas as pesquisas feitas sobre resiliência sempre se encontrou a importância de existir a relação entre a pessoa resiliente e um outro - um amigo, um parente, um conhecido, enfim, alguém com quem se possa compartilhar vivências e em quem se possa confiar.

Frankl (1946/1989a, 1990), quando explicita os caminhos através dos quais se descobre e vivencia o sentido, reporta-se à vivência de amar e ser amado por alguém. Novamente, coloca-se a questão do sentido. Com isto, estão de acordo Vanistandael e Lecomte (2004) ao relatarem que o amor ao próximo pode conferir sentido à existência e que a fé e uma filosofia de vida, expressas em uma religiosidade sem sectarismos, bem como a "capacidade de situar o acidente em uma perspectiva ampla, filosófica", ajudam a suportar e superar o sofrimento. "Uma pessoa resiliente descobre, por meio da fé, a possibilidade de ser aceita incondicionalmente" (Vanistandael \& Lecomte, 2004, p.95).

Aqui se torna importante o conceito de suprasentido de Frankl (1946/1989a). Para ele, muitas vezes é difícil ao ser humano compreender o porquê de certas situações dolorosas, porém, a pessoa precisa acreditar por meio da fé e do amor que, se a vida tem sentido, o sofrimento inevitável também o tem. Mesmo que seja quase impossível que este sentido seja entendido racionalmente em uma situação extrema inevitável, ele existe.

Frankl (1946/1989a, 1948/1993) enfatiza que o ser humano é livre para realizar um sentido e escolher o que fazer de sua vida, e esta liberdade expressa-se a cada momento presente, a cada instante. Como os momentos são transitórios, precisa-se vivenciar a atitude mais sensata, sem perder a chance de concretizá-la. Então, construir resiliência é algo que se faz a cada momento, a cada escolha.

Cada momento bem vivido passa a ser uma realização armazenada no terreno do passado (Frankl, 1948/1993). Ou seja, aquilo que foi bem vivido, o que foi experienciado de forma positiva, não pode ser mudado. Todo o passado não pode ser mudado. Então o bem vivido fica guardado no passado, como uma realidade. 
O sentido e realização no passado, relembrados, constituem forças para viver melhor o presente e suportar adversidades.

\section{Resiliência e autotranscendência}

Faz parte da existência humana olhar para fora de si, olhar para o outro, ou para um trabalho a ser realizado no mundo (Frankl, 1989b). A partir disto, como conseqüência, surge a força para resistir às adversidades.

Vanistendael e Lecomte (2004) afirmam que muitas pessoas, diante de um fato traumático, lançam-se para fora de si (autotranscendência) em direção ao altruísmo e ao testemunho. "O altruísmo não é só uma conseqüência, mas sim uma fonte de resiliência" (p.99).

\section{Resiliência e autodistanciamento: o papel do humor}

Diversos pesquisadores explicitaram a importância do humor como fator promotor de resiliência (Canelas, 2004; Job, 2000; Ojeda, 2002; Rodríguez, 2002; Walsh, 2004).

O humor permite uma descarga emocional que alivia a pessoa e permite enxergar a vida de forma otimista (Job, 2000). Produz um efeito tranqüilizante e prazeroso, permitindo que se aceite o que não se pode mudar. Toma-se distância do problema, libera-se o pensamento crítico, encontram-se respostas originais (Ojeda, 2002).

Rodríguez (2002) concorda com esta colocação quando explica que o humor sustenta a identidade grupal e liga-se a um raciocínio que "habilita uma visão alternativa que permita linhas de ação novas" (p.196). A criatividade envolvida no humor contribui para a resiliência.

\section{Resiliência e salutogênese}

Nesse ponto, é importante ressaltar uma concepção teórica que dá suporte à visão de resiliência e

574 pode ser tema de outro estudo em que também se verifique a contribuição de Frankl: a salutogênese (Ganyane, 2005).

A salutogênese, assim como a resiliência, é um construto que enfatiza a origem da saúde e os processos geradores de bem-estar, ao invés de priorizar o enfoque na adversidade e na doença (Canelas, 2004; Cuestas, Estamatti \& Melillo, 2002; Cyrulnik, 2001; Fontecilla \& Cáceres, 1997; Galende, 2004; Ganyane, 2005; Grotberg, 2002, Infante, 2002; Job, 2000; Kotliarenko, Kotliarenko \& Lecannelier, 2004; Melillo, Ojeda \& Rodríguez, 2004).

Salutogênese é uma palavra que etimologicamente origina-se do latim (salus, saúde) e do grego (genesis, origem) (Ganyane, 2005). Segundo esta visão, os estressores estão sempre presentes, porém não são positivos ou negativos em si. Assumem seu valor salutogênico ou não de acordo com a resposta do indivíduo a eles. Torna-se importante entender como as pessoas permanecem saudáveis apesar deles - o que vai ao encontro dos estudos de resiliência.

\section{Considerações Finais}

O ser humano tem a capacidade de se perceber vivo. Quando começa a pensar criticamente, ou quando lança seu olhar ao mundo, ou ainda conforme vive e reflete, ele nasce existencialmente e faz questionamentos que expressam sua surpresa e perplexidade diante da vida: pergunta-se quem é, o que faz aqui, o que é viver, por que a vida é tão desafiadora, por que existem injustiças e sofrimento. Quer saber se a vida de que dispõe é tudo o que terá, qual o motivo de ter nascido em determinado tempo e lugar, filho de determinados pais. Enfim, pergunta-se se a própria vida faz sentido.

Ao formular respostas a estes questionamentos com base na reflexão e na ação, a pessoa vai configurando sua existência: o caminho se faz ao caminhar. 0 ser humano tem a particularidade de decidir o que vai se tornar, e a questão do sentido mostra-se essencial: é necessário encontrar um sentido para a vida, um sentido que faça valer a pena viver, um sentido que motive a pessoa a levantar-se de manhã e encarar o novo dia, com seus desafios.

Para compreender a realidade, muitas vezes, buscam-se modelos, espelha-se em exemplos vivenciais, principalmente de familiares e pessoas significa- 
tivas, para começar a obter as pistas necessárias às respostas buscadas. Estas também vêm a partir das conseqüências das próprias escolhas e atos. Na medida em que o homem desempenha papéis sociais, na medida em que age e realiza suas tarefas, passa a conhecer-se, formando uma visão de mundo e encontrando um sentido para a vida.

O ser humano precisa encontrar coerência no mundo em que vive para se situar existencialmente. Vive em um mundo ordenado física e biologicamente; e sua mente, além de ordenada, é ordenadora. A confusão e a ambigüidade são vivenciadas como fontes de tensão e desprazer. Quando enfrenta estas angústias existenciais, pode fazer a grande descoberta: a de que este sentido só pode ser descoberto por ele mesmo e por mais ninguém. Cada um é responsável por descobrir o sentido de sua vida. E, na busca deste sentido, a angústia, o vazio e o tédio se dissipam.

Viktor Frankl, em sua obra, descreve as condições (pistas vivenciais) em que isto é possível. O conceito de resiliência mostra as conseqüências de se ter atingido tal objetivo. Compreender este conceito é compreender as condições pelas quais a pessoa pode vir a se tornar capaz de resistir às vicissitudes da vida, uma vez que esta, para a pessoa, é algo que faz sentido.

Em todo ser humano - uns mais, outros menos - o sofrimento atravessa o caminho da vida. Então, é preciso resistir ou, mais que isto, ser flexível como a árvore que se dobra pela pressão do vento e depois volta à posição original. Dobrar-se sem romper, aprender com a adversidade, dar a volta por cima, superar os traumas e dificuldades, encontrar alternativas. Crescer, renovar-se, reconstruir-se diante da dor. Encontrar recursos. Para tudo isso, surge a necessidade da resiliência. Todos precisam construir resiliência em certo grau.

A resiliência torna-se a operacionalização de algumas das conseqüências de se encontrar o sentido da vida.

Para ser resiliente é muito importante o suporte de pessoas (cuidadores) que transmitam apoio e confiança. Mas, mesmo na falta deste suporte, a forte crença em um sentido para a vida e o esforço para realizá-lo podem ser suficientes para superar a adversidade, com muito esforço. Com certeza, serão suficientes para que se assuma uma atitude corajosa diante do desafio que se apresenta - o obstáculo, a adversidade. Tudo isso foi comprovado por Frankl na experiência em que ele se viu prisioneiro de campos de concentração, mas manteve sua firmeza e seus valores, testemunhando com sua vida a possibilidade de transcender o sofrimento, o que se configura como uma conquista interior.

Construir resiliência é fomentar processos de salutogênese. $O$ trabalho de campo com estes construtos é um exercício de psicologia da saúde e dos recursos que existem nas pessoas e ao redor delas para lidar com a adversidade e, assim, viver com a melhor qualidade de vida possível, apesar dos fatores de risco.

O sentido da resiliência, então, é a busca de sentido da vida, que se traduz em criatividade, aprendizado, superação, crescimento. Dizer e viver um grande SIM à vida, apesar de tudo.

\section{Referências}

Canelas, R. S. (2004). A Resiliência de crianças em situação de risco em programas sócio-educativos de Belo Horizonte. Dissertação de mestrado não-publicada, Universidade Federal de Minas Gerais, Belo Horizonte.

Coelho Junior, A. G., \& Mahfoud, M. (2001). As dimensões espiritual e religiosa da experiência humana: distinções e inter-relações na obra de Viktor Frankl. Psicologia USP, $12(2), 95-103$.

Cuestas, A., Estamatti, M., \& Melillo, A. (2002). Algunos fundamentos psicológicos del concepto de resiliencia. In A. Melillo \& E. N. S. Ojeda, (Orgs.), Resiliencia: descobriendo las propias fortalezas (pp.83-102). Buenos Aires: Paidós.

Cyrulnik, B. (2001). La maravilla del dolor: el sentido de la resiliencia. Buenos Aires: Granica Editora.

Frankl, V. E. (1989a). Psicoterapia e sentido da vida. São Paulo: Quadrante (Originalmente publicado em 1946).

Frankl, V. E. (1989b). Um sentido para a vida. Aparecida: Santuário.

Frankl, V. E. (1990). A questão do sentido em psicoterapia. Campinas: Papirus .

Frankl, V. E. (1991a). A psicoterapia na prática. Campinas: Papirus.

Frankl, V. E. (1991b). Psicoterapia para todos: uma psicoterapia coletiva para contrapor-se à neurose coletiva. Petrópolis: Vozes.

Frankl, V. E. (1993). A presença ignorada de Deus. Petrópolis: Vozes. (Originalmente publicado em 1948).

Frankl, V. E. (1998). Senso e valori per l'esistenza: la risposta della logoterapia. Roma: Città Nuova Editrice. (Originalmente publicado em 1969). 
Frankl, V. E. (2006). Em busca de sentido: um psicólogo no campo de concentração. Petrópolis: Vozes.

Galende, E. (2004). Subjetividad y resiliencia: del azar y la complejidad. In A. Melillo, E. N. S. Ojeda \& D. Rodríguez (Orgs.), Resiliencia y subjetividad (pp.23-61). Buenos Aires: Paidós.

Ganyane, E. M. (2005). Gender differences in salutogenic functioning in military deployment. Un-published master's degree, University of South Africa, Pretoria, South Africa. Retireved September 5, 2007, from: http://etd.unisa. ac.za/ETD-db/theses/available/etd-11172005-114341/ unrestricted/00 front.pdf.

Giddens, A. (2002). Modernidade e identidade. Rio de Janeiro: Jorge Zahar Editor.

Grotberg, E. H. (2002). Nuevas tendencias en resiliencia. In A. Melillo \& E. N. S. Ojeda (Orgs.), Resiliencia: descobriendo las propias fortalezas (pp.19-30). Buenos Aires: Paidós.

Houaiss, A., \& Villar, M. S. (2001). Dicionário Houaiss da língua portuguesa. Rio de Janeiro: Objetiva.

Infante, F. (2002). La resiliencia como proceso: una revisión de la literatura reciente. In A. Melillo \& E. N. S. Ojeda (Orgs.). Resiliencia: descobriendo las propias fortalezas. (pp.31-53). Buenos Aires: Paidós.

Job, J. R. P. P. (2000). A escritura da resiliência: testemunhas do holocausto e a memória da vida. Tese de doutorado, não-publicada, Pontifícia Universidade Católica de São Paulo.

Kotliarenko, M. A., Fontecilla, M., \& Cáceres, I. (1997). Estado de arte en resiliencia. Washington, DC: Organización Panamericana de la Salud.

Kotliarenko, M. A., \& Lecannelier, F. (2004). Resiliencia y coraje: el apego como mecanismo protector. In A. Melillo, E. N. S. Ojeda \& D. Rodríguez (Orgs.), Resiliencia y subjetividad (pp.123-135). Buenos Aires: Paidós.
Lukas, E. S. (1996). Logo test: test para la medición de la "realización interior del sentido"y dela "frustración existencial". Buenos Aires: Editorial Almagesto.

Melillo, A. (2004a). Realidad social, psicoanálisis y resiliencia. In A. Melillo, E. N. S. Ojeda \& D. Rodríguez (Orgs.), Resiliencia y subjetividad (pp.63-76). Buenos Aires: Paidós.

Melillo, A. (2004b). Sobre la necessidad de especificar un nuevo pilar de la resiliencia. In A. Melillo, E. N. S. Ojeda \& D. Rodríguez (Orgs.), Resiliencia y subjetividad (pp.77-90). Buenos Aires: Paidós.

Melillo, A., Ojeda, E. N. S., \& Rodríguez, D. (2004). Resiliencia y subjetividad. Buenos Aires: Paidós.

Ojeda, E. N. S. (2002). Una concepción latinoamericana: la resiliencia comunitaria. In A. Melillo \& E. N. S. Ojeda (Orgs.), Resiliencia: descobriendo las propias fortalezas (pp.67-82). Buenos Aires: Paidós.

Peter, R. (1999). Viktor Frankl: a antropologia como terapia. São Paulo: Paulus.

Rodríguez, D. (2002). El humor como indicador de resiliencia. In A. Melillo \& E. N. S. Ojeda (Orgs.). Resiliencia: descobriendo las propias fortalezas (pp.185-196). Buenos Aires: Paidós.

Vanistendael, S., \& Lecomte, J. (2004). Resiliencia y sentido de vida. In A. Melillo, E. N. S. Ojeda \& D. Rodríguez (Orgs.), Resilienciay subjetividad (pp.91-101). Buenos Aires: Paidós.

Walsh, F. (2004). Resiliencia familiar: estratégias para su fortalecimiento. Madrid: Amorrortu Editores.

Xausa, I. A. M. (1988). A psicologia do sentido da vida. Petrópolis: Vozes.

Recebido em: 31/10/2006

Versão final reapresentada em: 26/10/2007

Aprovado em: 26/11/2007 